\title{
Study on Nutritional Requirements of Nematophagous Fungi in Terms of Carbon and Nitrogen Sources
}

\author{
Anamika $^{1}$ \\ ${ }^{1}$ Department of Agriculture, CAFF, Fiji National University, Fiji Island \\ Correspondence: Anamika, Department of Agriculture, CAFF, Fiji National University, Fiji Island. E-mail: \\ anamika_bhu01@rediffmail.com
}

Received: October 10, 2014 Accepted: March 16, 2015 Online Published: May 15, 2015

doi:10.5539/jas.v7n6p227 URL: http://dx.doi.org/10.5539/jas.v7n6p227

\begin{abstract}
Nematophagous fungi act as natural enemies for biological control of plant parasitic nematodes. Dactylaria eudermata and Arthropotrys oligospora are the nematohogous fungi producing one to three dimensional hyphal bails and adhesive nets as a capturing device were selected and it was observed that growth and trapping effectiveness is influenced by temperature and C:N ratio. For the assessment of favorable temperature radial growth of both the fungi was studied at different temperature and $25^{\circ} \mathrm{C}$ was recorded as an optimum temperature. Carbon and nitrogen content in media affect their predacity against plant parasitic nematode so their growth and sporulation were studied by providing different carbon and nitrogen sources. Among carbon sources, Glucose was the best source for both the fungi whereas Potassium nitrate for D. eudermata and Sodium nitrate for $A$. oligospora were recorded as the best Nitrogen sources.
\end{abstract}

Keywords: Dactylaria eudermata, Arthropotrys oligospora, temperature, carbon and nitrogen sources

\section{Introduction}

Nematode trapping fungi are responsible for keeping the nematode population in check and are an important part of the subsoil ecosystem. Nematophagous fungi predominantly present in the soil as saprophytes but act as parasites in presence of nematodes so as to fulfill the requirements of additional nutrient source in terms of nutritional advantage. The fungi converts its saprophytic stage to their parasitic phase and change their morphological structure into traps or mature spores. The development of infection structures is a prerequisite for the trapping of nematodes. The nematodes releases nemin like chemical substances which evokes the fungi to form trapping devices and these devices attracts nematodes towards itself and finally nematodes are trapped. If nematophagous fungi can be weaponized against nematode disease, then we will be able to see an even more noticeable difference. These fungi comprise more than 200 species found in all major taxonomic groups including lower (oomycetes, chytridiomycetes, zygomycetes) and higher fungi (ascomycetes, basidiomycetes and deuteromycetes). Most of them, including both nematode trapping and endoparasitic species, are asexual fungi (deuteromycetes), that all share the ability to attack living nematodes and use them as nutrients (Nordbring-Hertz et al., 2002). The nematophagous fungi, which infect nematodes with their conidia, are mostly more dependent on nematodes as a nutrient and are considered as obligate parasites (Jansson \& Nordbring-Hertz, 1979; Jansson, 1982). These fungi are widely distributed in all types of agricultural soils but they are abundant in dung or surface litter and decaying plant debris. These fungi act on the principle of attraction, adhesion, penetration and killing live nematodes and digest it by producing fascinating trapping devices. The ability to capture nematodes is connected with the development of structures on the fungal mycelia. The nematophagous fungi have formed hyphal structures, such as adhesive hyphal nets, knobs, branches and constricting or non-constricting rings, in which nematodes are captured by adhesion or mechanically. Fungal hyphae then penetrate the nematode and utilize its content for food. Many nematode trapping deuteromycetes are indeed also good saprophytes and have evolved among cellulolytic or lignolytic fungi, they can use cellulose and other polysaccharides as carbon sources (Barron, 1992). The nitrogen content is less in plant debris and due to extremely low nitrogen levels, nematophagous fungi have evolved parasitic behavior to satisfy their nitrogen requirements as nutritional demands (Thorn \& Barron, 1984; Barron, 2003). Also in the soil environments with a high carbon: nitrogen ratio, nematodes might serve as an important source of nitrogen. Part of the problem is that fungus population density, and especially trapping, is difficult to quantify in soil. Moreover, trapping usually 
cannot be inferred simply from suppression of nematodes following organic amendment because such amendments can suppress nematodes in many different ways (Wang et al., 2002; Widmer et al., 2002). With organic matter of a C:N ratio greater than 20:1, $\mathrm{N}$ will temporarily be immobilized in microbial tissue, creating a nitrogen deficiency (Akhtar \& Malik, 2000). The nematode management potential of an organic soil amendment is directly related to N-content or inversely related to the C:N ratio (Mian \& Rodriguez-Kabana, 1982a, 1982b). Therefore it is necessary to study about the different sources of carbon and nitrogen with respect to the temperature as changes in climatic condition also affect the growth and development of the nematophagous fungi. So the objectives of the study were taken to determine the suitable temperature and appropriate carbon nitrogen sources for the radial growth of $D$. eudermata and A. oligospora in vitro condition.

\section{Materials and Methods}

Isolation of nematophagous fungi (Dactylaria eudermata and Arthrobotrys oligospora) was done from the soil sample collected from different villages of Allahabad, India by the method described by Duddington (1955). Single spore isolation technique (Tuite, 1969) was used for obtaining the pure culture of both D. eudermata and A. oligospora and were maintained on maize meal agar and used for further experiment.

\subsection{Temperature Effect on Radial Growth of D. eudermata and A. oligospora}

Maize meal agar medium was selected as an ideal medium to check the temperature effect on radial growth of both the fungi. $5 \mathrm{~mm}$ fungal disc of both the fungus were cut from the periphery of seven days old culture with the help of sterilized cork borer and inoculated into Petri dishes containing cooled and solidified maize meal agar medium and were incubated at $15,20,25,30$ and $35^{\circ} \mathrm{C}$.

Three petriplates were used for both fungi at varied temperature. Radial growths were measured on $6^{\text {th }}$ days of inoculation and experiment was repeated three times in Complete Randomize Design and pooled data was subjected to statistical analysis.

\subsection{Effect of Different Carbon Sources on Radial Growth of D. eudermata and A. oligospora}

The radial growths of both the fungus (D. eudermata and A. oligospora) were studied on Yeast extract peptone soluble starch (YPSS) medium. The carbon source of this medium soluble starch was replaced by five other carbon sources, viz. Dextrose, Sucrose, Glucose, Mannitol and Fructose. Medium with soluble starch served as check. All the culture media were prepared, sterilized and poured separately into several sterilized Petri dishes. 5 $\mathrm{mm}$ fungal disc, duly cut with a sterilized cork borer, were taken from the periphery of seven days old culture and inoculated into Petri dishes containing different media. Three replications were maintained for each treatment and were incubated at $25 \pm 1^{\circ} \mathrm{C}$.

Radial growth and sporulation of both the fungus was measured after six days. The experiment was repeated three times in Complete Randomize Design and pooled data was subjected to statistical analysis.

\subsection{Effect of Nitrogen Sources on Radial Growth of D. eudermata and A. oligospora}

The radial growth of both the fungus ( $D$. eudermata and A. oligospora) was studied on Czapek's medium. The nitrogen source of this medium sodium nitrate was replaced by five other nitrogen sources, viz. Calcium nitrate, Ammonium nitrate, Ammonium chloride, Potassium nitrate and Ammonium sulphate. Medium with Sodium nitrate served as check. All the culture media were prepared, sterilized and poured separately into several sterilized Petri dishes. $5 \mathrm{~mm}$ fungal disc were taken from the periphery of seven days old culture with a sterilized cork borer and inoculated into Petri dishes containing different media. Three replications for each treatment were maintained and incubated at $25 \pm 1{ }^{\circ} \mathrm{C}$.

Radial growth and sporulation of both the fungus was measured after six days. The experiment was repeated three times in Complete Randomize Design and pooled data was subjected to statistical analysis.

\section{Results and Discussion}

\subsection{Temperature Effect on the Radial Growth of Nematophagous Fungi}

The effect of temperature on the radial growth of the both nematophagous fungi are presented in Table 1 (Figure 1). Radial growth of the test fungi was significantly influenced by temperature. For the radial growth of the fungus at different temperature, $25^{\circ} \mathrm{C}$ was recorded as an optimum temperature. From the observations recorded, it is quite clear that at this optimum temperature A. oligospora grows faster than D. eudermata. In general, radial growth of both the fungus showed decrease in growth with increase or decrease in temperature beyond the optimum temperature. At $30{ }^{\circ} \mathrm{C}$ the growth was appreciable while above $30{ }^{\circ} \mathrm{C}$, the growth rate decreased significantly. At temperature below $20^{\circ} \mathrm{C}$, the growth of both the fungus was also very slow. 
Table 1. Effect of temperature on growth of nematophagous fungi in MMA medium

\begin{tabular}{llll}
\hline \multirow{2}{*}{ Temperature $\left({ }^{\circ} \mathbf{C}\right)$} & \multicolumn{2}{c}{ Radial Growth (mm) After 6 Days } & \multirow{2}{*}{ Nematophagous fungi } \\
\cline { 2 - 3 } & \multicolumn{2}{c}{ D. eudermata } & A. oligospora \\
\hline $\mathrm{T}_{1}(15)$ & 15.2 & 16.2 & 15.7 \\
$\mathrm{~T}_{2}(20)$ & 34.8 & 40.5 & 37.6 \\
$\mathrm{~T}_{3}(25)$ & 69.1 & 78.2 & 73.6 \\
$\mathrm{~T}_{4}(30)$ & 65.5 & 71.5 & 68.5 \\
$\mathrm{~T}_{5}(35)$ & 58.2 & 60.2 & 59.2 \\
Mean & 48.5 & 53.3 & 50.9 \\
$\mathrm{~F}-\mathrm{Test}$ & $\mathrm{S}$ & $\mathrm{S}$ & \\
$\mathrm{SEm} \pm$ & 0.49 & 0.98 & \\
$\mathrm{CD}(\mathrm{P}=0.05)$ & 1.09 & 1.088 & \\
\hline
\end{tabular}

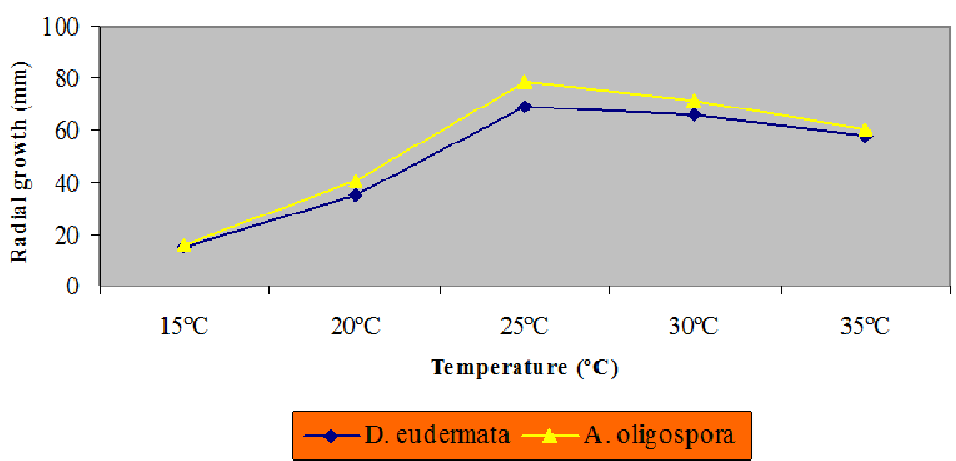

Figure 1. Effect of temperature on growth of nematophagous fungi in MMA medium

Similar observations on different temperature effect for different fungi have been reported by earlier workers. Pandey (1973) reported that $25^{\circ} \mathrm{C}$ as optimum temperature for Arthrobotrys robusta while Gueye et al. (1997) found optimal growth of $A$. musiformis at $25-30^{\circ} \mathrm{C}$.

\subsection{Effect of Carbon Sources on the Radial Growth of D. eudermata and A. oligospora}

Data on the radial growth of $D$. eudermata and A. oligospora on different carbon sources are presented in Table 2 (Figure 2). Among the carbon sources, glucose supported maximum radial growth of $D$. eudermata followed by fructose. Mannitol, however, supported minimum growth in comparison to other carbon sources. Starch, sucrose and Dextrose also supported moderate growth of this fungus. The radial growth of $D$. eudermata on different carbon sources was recorded in the following order:

Glucose $>$ Fructose $>$ Starch $>$ Sucrose $>$ Dextrose $>$ Mannitol

The test fungus D. eudermata sporulates well in all the test carbon sources. However, excellent sporulation of the fungus was observed on glucose followed by dextrose.

Glucose also supported maximum growth of A. oligospora followed by starch. Mannitol however, supported minimum rate of growth in comparison to glucose and Starch. Fructose, sucrose and dextrose showed appreciable growth of this fungus. The radial growth of A. oligospora on different carbon sources was recorded in the following order:

Glucose $>$ Starch $>$ Fructose $>$ Sucrose $>$ Dextrose $>$ Mannitol

The test fungus A. oligospora sporulates in all the tested carbon sources. However, excellent sporulation of the fungus was observed in glucose and starch followed by fructose. Similar observation on glucose as best carbon sources for different fungi have been reported by earlier workers (Ajello, 1948; Colderone \& Barnett, 1972; 
Srivastava, 1981; Prasad, 1985; Singh, 2007).

Table 2. Effect of carbon sources on the radial growth of nematophagous fungi

\begin{tabular}{|c|c|c|c|c|}
\hline \multirow{3}{*}{ Treatments } & \multicolumn{4}{|c|}{ Nematophagous fungi } \\
\hline & \multicolumn{2}{|c|}{ D. eudermata } & \multicolumn{2}{|c|}{ A. oligospora } \\
\hline & Radial Growth (mm) & Sporulation & Radial Growth (mm) & Sporulation \\
\hline $\mathrm{T}_{0}(\mathrm{Starch})$ & 73.1 & +++ & 86.3 & +++++ \\
\hline $\mathrm{T}_{1}$ (Fructose) & 75.1 & +++ & 83.2 & ++++ \\
\hline $\mathrm{T}_{2}$ (Dextrose) & 65.9 & ++++ & 76.9 & ++ \\
\hline $\mathrm{T}_{3}$ (Sucrose) & 70.1 & ++ & 81.2 & +++ \\
\hline $\mathrm{T}_{4}$ (Mannitol) & 54.5 & + & 64.9 & + \\
\hline $\mathrm{T}_{5}$ (Glucose) & 77.9 & +++++ & 89.1 & +++++ \\
\hline Mean & 69.4 & & 80.2 & \\
\hline $\mathrm{F}$ - Test & S & & $\mathrm{S}$ & \\
\hline $\operatorname{SEm} \pm$ & 0.64 & & 0.68 & \\
\hline $\mathrm{CD}(\mathrm{P}=0.05)$ & 1.39 & & 1.47 & \\
\hline
\end{tabular}

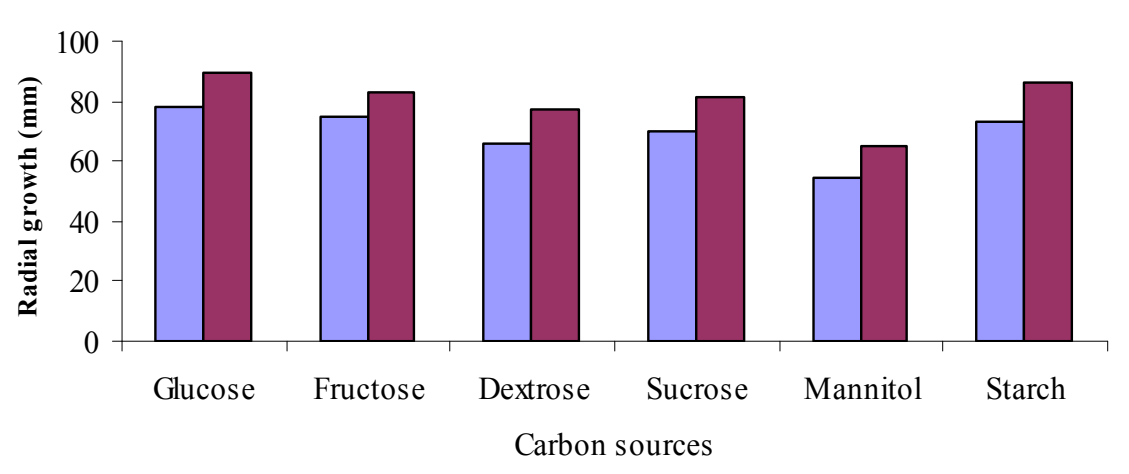

$\square$ D. eudermata $\square$ A. oligospora

Figure 2. Effect of carbon source on the radial growth of nematophagous fungi

\subsection{Effect of Nitrogen Sources on the Growth of D. eudermata and A. oligospora}

Data recorded in Table 3 (Figure 3) shows that the radial growth of D. eudermata and A. oligspora differ significantly on different nitrogen sources. In case of D. eudermata, among six nitrogen sources, potassium nitrate supported maximum radial growth followed by sodium nitrate and calcium nitrate. Ammonium chloride was found to be the poorest source of nitrogen. The radial growth of $D$. eudermata on different nitrogen sources was recorded in the following order:

Potassium nitrate $>$ Sodium nitrate $>$ Calcium nitrate $>$ Ammonium nitrate $>$ Ammonium sulphate $>$ Ammonium chloride

Among six nitrogen sources, sodium nitrate was found to be the best for the radial growth of A. oligospora followed by potassium nitrate and calcium nitrate while ammonium sulphate was found to be the poorest source of nitrogen. The radial growth of $A$. oligospora on different nitrogen sources were recorded in the following order:

Sodium nitrate $>$ Potassium nitrate $>$ Calcium nitrate $>$ Ammonium nitrate $>$ Ammonium chloride $>$ Ammonium sulphate

Both the fungus sporulate in all the six nitrogen sources tested except $D$. eudermata does not sporulate on ammonium chloride, while A. oligospora sporulated comparatively lesser in ammonium chloride. Excellent 
sporulation of both the fungus was observed in sodium nitrate and potassium nitrate. Similar observations on best nitrogen sources for different fungi have been reported by earlier workers (Lilly \& Barnett, 1951; Srivastava, 1981; Prasad, 1985; Subramanian \& Tyagi, 1968). The capacity of $D$. eudermata and A. oligospora to use nitrate indicate that the fungi produces reductase enzyme or other associated enzymes like hypernitrite reductase and hydroxylamine reductase, involved in the metabolism of the nitrate (Walker \& Nicholas, 1962; Medina \& Nicholas, 1957; Singh, 2007). The fungal growth in carbon and nitrogen deficient media may be accredited to the presence of these sources in form of impurities in other chemicals used during study.

Table 3. Effect of nitrogen sources on the radial growth of nematophagous fungi

\begin{tabular}{|c|c|c|c|c|}
\hline \multirow{3}{*}{ Treatments (Nitrogen Sources) } & \multicolumn{4}{|c|}{ Nematophagous fungi } \\
\hline & \multicolumn{2}{|c|}{ D. eudermata } & \multicolumn{2}{|c|}{ A. oligospora } \\
\hline & Radial Growth (mm) & Sporulation & Radial Growth (mm) & Sporulation \\
\hline $\mathrm{T}_{0}$ (Sodium Nitrate) & 75.3 & +++++ & 88.5 & +++++ \\
\hline $\mathrm{T}_{1}$ (Potassium Nitrate) & 78.6 & ++++ & 84.9 & +++++ \\
\hline $\mathrm{T}_{2}$ (Calcium Nitrate) & 72.1 & +++ & 82.1 & +++ \\
\hline $\mathrm{T}_{3}$ (Ammonium Nitrate) & 69.5 & ++ & 74.5 & ++ \\
\hline $\mathrm{T}_{4}$ (Ammonium Chloride) & 61.2 & - & 68.2 & + \\
\hline $\mathrm{T}_{5}$ (Ammonium Sulphate) & 64.5 & + & 64.5 & ++ \\
\hline Mean & 70.2 & & 77.1 & \\
\hline $\mathrm{F}-$ Test & $\mathrm{S}$ & & $\mathrm{S}$ & \\
\hline $\mathrm{SEm} \pm$ & 0.44 & & 0.46 & \\
\hline $\mathrm{CD}(\mathrm{P}=0.05)$ & 0.95 & & 1.00 & \\
\hline
\end{tabular}

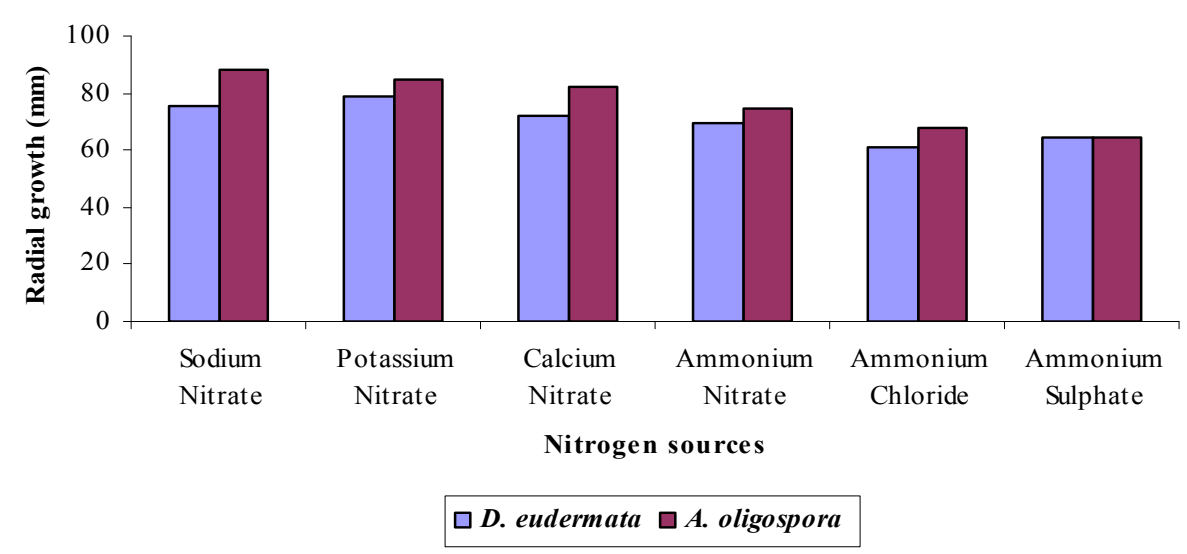

Figure 3. Effect of nitrogen sources on the radial growth of nematophagous fungi

\section{Acknowledgements}

Author is thankful to Professor Sobita Simon for constant help and moral support in conducting the experiments.

\section{References}

Ajello, L. (1948). A Cytological and Nutritional Study of Polychytrium aggregatum. Part II. Nutrition. American J. Bot., 35, 135-140. http://dx.doi.org/10.2307/2438236

Akhtar, M., \& Malik, A. (2000). Roles of organic soil amendments and soil organisms in the biological control of plant-parasitic nematodes. A Review. Bioresour. Technol., 74, 35-47. http://dx.doi.org/10.1016/S0960-8524(99)00154-6

Barron, G. L. (1992). Lignolytic and Cellulolytic fungi as predators and parasites. In G. C. Carroll \& D. T. Wicklow (Eds.), The Fungal Community, its Organization and Role in the Ecosystems (pp. 311-326). 
Marcel Dekker, New York.

Barron, G. L. (2003). Predatory fungi, wood decay, and the carbon cycle. Biodiversity, 4, 3-9. http://dx.doi.org/10.1080/14888386.2003.9712621

Coldrone, R. A., \& Barnett, H. L. (1972). Axenic growth and nutrition of gonatobotryum fuscum. Mycologia, 64, 153-164. http://dx.doi.org/10.2307/3758023

Duddington, C. L. (1955). Notes on the technique of handling predacious fungi. Trans. Brit. Mycol. Soc., 38(2), 97-103. http://dx.doi.org/10.1016/S0007-1536(55)80021-6

Gueye, M., Duponnois, R., Samb, P. I., \& Mateille, T. (1997). Study on 3 strains of Arthrobotrys oligospora: Biological characterization and effects on Meloidogyne mayaguensis parasitic on tomato in Senegal. Tropicultura, 15(3), 109-115.

Jansson, H. B. (1982). Attraction of nematodes to endoparasitic nematophagous fungi. Transactions of the British Mycological Society, 79, 25-29. http://dx.doi.org/10.1016/S0007-1536(82)80187-3

Jansson, H. B., \& Norbring-Hertz, B. (1979). Attraction of nematodes to living mycelium of nematophagous fungi. Journal of General Microbiology, 112, 89-93. http://dx.doi.org/10.1099/00221287-112-1-89

Lilly, V. G., \& Barnett, H. L. (1951). Physiology of fungi. Mc Graw Hill, New York.

Medina, A., \& Nicholas, D. J. D. (1957). Hyponitrite Reductase in Neurospora. Nature, 179, 533-534. http://dx.doi.org/10.1038/179533a0

Mian, I. H., \& Rodriguez-Kabana, R. (1982b). Soil amendments with oilcakes and chicken litter for control of Meloidogyne arenaria. Nematropica, 12, 205-220.

Mian, I. H., \& Rodriguez-Kabana, R. (1982a). Organic amendments with high tannin and phenolic contents for control of Meloidogyne arenaria in infested soil. Nematropica, 12, 221-234.

Nordbring-Hertz, B., Jansson, H. B., \& Tunlid, A. (2002). Nematophagous fungi. Encyclopedia of Life Science, $12,681-690$.

Pandey, V. S. (1973). Predatory activity of nematode trapping fungi against the larvae of Trichostrongylus axei and Ostertagia ostertagi: A possible method of biological control. Journal of Helminthology, XLVII(1), 35-48. http://dx.doi.org/10.1017/S0022149X00023725

Prasad, G. (1985). Studies on nematophagous fungi (Ph.D. Thesis). Mycology and Plant Pathology, I.A.S., Bananas Hindu University.

Singh, U. B. (2007). Ocuurance Characterization and Performance of some Predacious Fungi (M.Sc Thesis). Banaras Hindu University.

Srivastava, S. S. (1981). Studies on some predaceous fungi (Ph.D. Thesis). Banaras Hindu University.

Subramanian, C. V., \& Tyagi, P. D. (1968). Proc. Indian Acad. Sci., 58, 111-129.

Tuite John. (1969). Plant Pathological Methods (pp. 1-81). Burges Publishing Company, USA.

Walker, C. G., \& Nicholas, D. J. D. (1962). An Iron Requirement for a Dissimilatory Nitrate Reductase in Neurospora crassa. Nature, 189, 141-142. http://dx.doi.org/10.1038/189141a0

Wang, K. H., Sipes, B. S., \& Schmitt, D. P. (2002). Crotalaria as a cover crop for nematode management: A review. Nematropica, 32, 35-57.

Widmer, T. L., Mitkowski, N. A., \& Abawi, G. S. (2002). Soil organic matter and management of plant-parasitic nematodes. Journal of Nematology, 34, 289-295.

\section{Copyrights}

Copyright for this article is retained by the author(s), with first publication rights granted to the journal.

This is an open-access article distributed under the terms and conditions of the Creative Commons Attribution license (http://creativecommons.org/licenses/by/3.0/). 